\title{
The Danish Depression Database
}

This article was published in the following Dove Press journal:

Clinical Epidemiology

25 October 2016

Number of times this article has been viewed

\section{Poul Videbech' \\ Anette Deleuran² \\ 'Mental Health Centre Glostrup, Department of Clinical Medicine, University of Copenhagen, Glostrup, \\ ${ }^{2}$ Psychiatric Centre Amager, \\ Copenhagen S, Denmark}

Aim of database: The purpose of the Danish Depression Database (DDD) is to monitor and facilitate the improvement of the quality of the treatment of depression in Denmark. Furthermore, the DDD has been designed to facilitate research.

Study population: Inpatients as well as outpatients with depression, aged above 18 years, and treated in the public psychiatric hospital system were enrolled.

Main variables: Variables include whether the patient has been thoroughly somatically examined and has been interviewed about the psychopathology by a specialist in psychiatry. The Hamilton score as well as an evaluation of the risk of suicide are measured before and after treatment. Whether psychiatric aftercare has been scheduled for inpatients and the rate of rehospitalization are also registered.

Descriptive data: The database was launched in 2011. Every year since then $\sim 5,500$ inpatients and 7,500 outpatients have been registered annually in the database. A total of 24,083 inpatients and 29,918 outpatients have been registered. The DDD produces an annual report published on the Internet.

Conclusion: The DDD can become an important tool for quality improvement and research, when the reporting is more complete.

Keywords: quality assurance, suicide, somatic diseases, national database

\section{Introduction}

Depression is a common and serious disease with prevalence of $3 \%$ in Denmark. ${ }^{1,2}$ At any given time, $\sim 150,000$ Danes thus suffer from moderate-to-severe depression according to the International Classification of Diseases, 10th version (ICD-10). The World Health Organization expects depression to be the second leading cause of world disability by 2020 and by 2030 it is expected to be the largest contributor to the disease burden worldwide. ${ }^{3}$

The treatment results are often unsatisfactory as many cases become chronic and during the last 15 years, an increasing number of patients receive disability pensions. ${ }^{4-6}$ Furthermore, many patients are readmitted several times. Assessing the quality of care has thus become increasingly important given the development over the last 30 years. While the number of available psychiatric beds in Denmark has been reduced by $60 \%-70 \%$, the number of treated patients is doubled in the same period. ${ }^{7}$

\section{Aim of database}

On this background, the development of the Danish Depression Database (DDD) as a national register for clinical quality started in 2008 within the Danish National Indicator 
Project framework. ${ }^{8}$ The register was established through collaboration among the Ministry of Health, the National Health and Medicines Authority, the Danish Regions, health care professional organizations, and scientific societies.

The aim was to assess and improve the quality of treatment and care to all patients with depression referred to psychiatric hospitals in Denmark with particular focus on the effects of treatment, evaluation of suicide risk, and the transition from inpatient to outpatient status. The database was fully functional in 2011 and since 2012 the DDD has published an annual report on data registered the past year.

\section{Study population}

The database contains data on depressed patients, who have either been admitted to one of the nearly 60 psychiatric hospital wards or treated at one of the 190 hospital outpatient clinics in Denmark. Since no private psychiatric hospitals exist in Denmark, the registration of depression requiring admission is complete. However, most cases with mildto-moderate depression are treated by general practitioners or specialists in psychiatry working in private practice, and are thus not registered in DDD. Also the few individuals hospitalized in a nonpsychiatric hospital and being treated for depression are not included in the database.

The following disorders are included according to the ICD-10: F32 Depressive episode, F33 Recurrent depressive disorder, F34.1 Dysthymia, and F06.32 Organic depressive disorder. Patients with other psychiatric diagnoses with lower F-numbers (eg, schizophrenia) are excluded, whereas persons with for instance depression and a personality disorder are not.

Participation in the DDD is mandatory for all Danish psychiatric hospitals, relevant clinical departments, and units treating patients with depression. As mentioned, private outpatient clinics exist in Denmark but these are not yet included in the reports from the DDD.

Only patients aged above 18 years with permanent residence in Denmark are registered in the database. Readmissions were combined to one period, in case the first contact was closed $<4$ days prior to any new admission in the same hospital. The same principle was applicable to outpatient contacts.

From the Danish National Patient Register, the codes of diagnosis and date of admission or inclusion in an outpatient clinic are gathered. As this registration is mandatory, nearly $100 \%$ data completeness is obtained. The data representing the indicators mentioned in the following is reported by the treating clinicians and thus added to the records from the
Danish National Register of Patients. This data is, however, not complete and highly dependent on the amount of work delivered from the local department.

All five regions in Denmark have contributed to the database since it was launched in 2011. Approximately 5,500 inpatients and 7,500 outpatients have been registered in the database each year, but the completeness of the individual indicators vary from department to department and from region to region. For instance, it is mandatory in Denmark to have a physical examination at admission to a psychiatric ward, but the indicator is only filled in $\sim 40 \%$ of the cases. One of the reasons for this meager result is that, for technical reasons, it is not possible to identify the individual ward in a department, which hinders optimization of the registration process in the individual wards. A total of 24,083 inpatients and 29,918 outpatients have been registered. Admissions shorter than 24 hours have been removed, as these are typically visits in a psychiatric emergency room and short admissions for electroconvulsive treatment.

The annual report from the register makes comparisons between regions and individual departments in Denmark possible.

\section{Main variables and the rationale behind them}

The DDD includes a number of process indicators and data on the number of treated patients, and to what extent the hospitals and the outpatient clinics fulfilled each indicator. The indicators assessing particular health structures, processes, and outcomes were selected by a panel of experts consisting of psychiatrists, psychologists, nurses, occupational therapists, and social workers. Several indicators were found relevant, but since the registration had to be manageable for the clinicians who were going to report the data, the total number of indicators was reduced to 13 .

The definitions of the indicators within the DDD are listed in Table 1. The main indicators are:

- Has the patient been thoroughly somatically examined? This was considered important, as several studies have shown an increased mortality due to somatic diseases among patients with depression. ${ }^{9}$

- Has the psychopathology of the patient been assessed by a psychiatric specialist within 7 days of admission? Due to lack of psychiatrists in Denmark, this is a huge problem. ${ }^{7}$ Specially trained psychologists and nurses assess many patients supervised by a psychiatrist, but interview face-to-face with a psychiatrist is considered important for instance in cases with depression secondary 
Table I Review of indicators of quality in treatment in the Danish Depression Database

\begin{tabular}{|c|c|c|}
\hline \multicolumn{2}{|c|}{ Indicator } & \multirow[b]{2}{*}{$\begin{array}{l}\text { Definition } \\
\text { Indication of whether the patient's psycho- } \\
\text { pathological assessment was performed by } \\
\text { a specialist in psychiatry within } 7 \text { days after } \\
\text { admittance to the hospital ward (for inpatients) } \\
\text { or within } 30 \text { days (for outpatients) }\end{array}$} \\
\hline I & $\begin{array}{l}\text { Examination by } \\
\text { psychiatrist }\end{array}$ & \\
\hline 2 & $\begin{array}{l}\text { Somatically } \\
\text { examined }\end{array}$ & $\begin{array}{l}\text { Neurological examination, relevant laboratory } \\
\text { tests and other examinations within } \\
2 \text { days (for inpatients) or within } 30 \text { days } \\
\text { (for outpatients) }\end{array}$ \\
\hline 3 & $\begin{array}{l}\text { Assessment by } \\
\text { social worker }\end{array}$ & $\begin{array}{l}\text { Assessment of need for acute or longer- } \\
\text { term support, such as help with changing } \\
\text { housing, financial help to purchase medicine, } \\
\text { educational guidance, rehabilitation, and } \\
\text { application for disability benefits }\end{array}$ \\
\hline 4 & $\begin{array}{l}\text { HAM-DI7 } \\
\text { assessment (I) }\end{array}$ & $\begin{array}{l}\text { Initial assessment using HAM-DI } 7 \text { within } \\
7 \text { days (for inpatients) or within } 30 \text { days } \\
\text { (for outpatients) }\end{array}$ \\
\hline 5 & $\begin{array}{l}\text { HAM-DI7 } \\
\text { assessment (II) }\end{array}$ & $\begin{array}{l}\text { Assessment using HAM-DI7 at discharge } \\
\text { from hospital or at termination of outpatient } \\
\text { treatment }\end{array}$ \\
\hline 6 & $\begin{array}{l}\text { Suicide risk } \\
\text { assessment (I) }\end{array}$ & $\begin{array}{l}\text { Using structured interview at admittance or at } \\
\text { start of treatment (outpatients) }\end{array}$ \\
\hline 7 & $\begin{array}{l}\text { Suicide risk } \\
\text { assessment (II) }\end{array}$ & $\begin{array}{l}\text { Clinician's assessment of the patient's risk of } \\
\text { suicide when discharge from hospital is planned }\end{array}$ \\
\hline 8 & Psychotherapy & $\begin{array}{l}\text { Psychotherapy offered to outpatients } \\
<90 \text { days after first visit }\end{array}$ \\
\hline 9 & $\begin{array}{l}\text { Contact with } \\
\text { relatives }\end{array}$ & $\begin{array}{l}\text { Staff contact with the patient's relatives during } \\
\text { hospitalization or }<90 \text { days after first visit for } \\
\text { outpatient }\end{array}$ \\
\hline 10 & $\begin{array}{l}\text { Psychiatric } \\
\text { aftercare }\end{array}$ & $\begin{array}{l}\text { Concrete agreement involving professional } \\
\text { support for inpatients after discharge }\end{array}$ \\
\hline II & Rehospitalization & Rehospitalization within 30 days after discharge \\
\hline 12 & Deceased & Deceased within 30 days after discharge \\
\hline 13 & Deceased & Deceased during stay in hospital \\
\hline
\end{tabular}

Abbreviation: HAM-DI7, Hamilton depression scale (17-item version).

to medical or neurological conditions. According to the registration in the DDD, only between a third and a half of the depressed patients are interviewed by a specialist in psychiatry within the first week. There is, however, considerable variation from department to department.

- Has psychiatric aftercare been scheduled for inpatients? Apart from effective acute management, care for hospitalized patients must include efficient transfer from hospital services to community-based services. However, patients with depression and other psychiatric disorders often fail to adhere to treatment after hospital discharge, which has been connected with relapse, rehospitalization, and suicide across diagnoses. ${ }^{10}$ An American study of 3,113 psychiatric admissions showed that patients who did not have an outpatient appointment after discharge were twice as likely to be rehospitalized in the same year. ${ }^{11}$ It appears from the DDD that aftercare has been scheduled for inpatients in only $40 \%-60 \%$ of the cases. Again there is considerable variation from department to department.

- Is the patient readmitted within 30 days? The 30-day rehospitalization rate may be the best indicator of the effectiveness of the care received during an admission, ${ }^{11}$ but as mentioned, efficient transfer to the general practitioner or other community-based services are also of importance. However, the efforts to contain the costs of treating depression and other psychiatric disorders have as mentioned implied a reduction in psychiatric beds, which again has resulted in shorter terms of inpatient care and therefore higher rates of hospital readmission. The rehospitalization rate was therefore considered important to monitor. In 2014, it was $10 \%$ on the average in Denmark for depressed patients with some variation across the country.

\section{Follow-up}

Each patient is interviewed with the Hamilton depression scale (17-item version) at admission to a hospital and after discharge as well as when starting and terminating outpatient treatment. The Hamilton depression scale is widely used in Denmark and video-clips of Hamilton-interviews have been made for educating the staff. In the same vein, the suicide risk is systematically assessed both before and after treatment. This is considered very important as studies have shown two large peaks of risk for suicide around psychiatric hospitalization, one in the first week after admission and another in the first week after discharge. ${ }^{12}$

Luckily, very few patients die during admission (12 out of 6,514 patients in 2014) or within the first month after discharge $(n=26)$ but such unfortunate events are also monitored. It is not possible to meaningfully compare different departments because the numbers are so small, but the affected hospitals are thus able to make a journal audit to investigate possible ways of preventing the events. The data on mortality as well as readmittances are drawn from the mandatory registers and thus data completeness is achieved.

The report from the DDD from 2014 is available on the Internet. ${ }^{13}$

\section{Examples of research}

At the time when the DDD was launched, the psychiatric service was under massive pressure due to lack of doctors and concomitantly accreditation according to "The Danish Quality model". During the last years, several new computer systems containing the patient records have been implemented, which 
also has put a drain on doctors' forces. Therefore, it has shown very difficult to obtain completeness of the clinicians' registrations. The database has thus only been used for few research projects, for instance, a study with the research question "Can large hospitals provide better quality of treatment to depressed patients than small hospitals?", to be published. Furthermore, studies are on their way to validate the information in the DDD by comparing randomly drawn samples of data with the corresponding patient records.

\section{Administrative issues and funding}

The DDD is part of the Danish Clinical Registries ${ }^{14}$ that constitute the infrastructure of National Clinical Quality Databases. The Clinical Registries in Denmark are founded on a national initiative, mandated by law and regulated by national government, but financed and owned by regional governments.

\section{Conclusion}

Data is collected from a national register comprising patients receiving hospital treatment in the Danish Health Care System as both inpatients and outpatients, which is rare in an international context. All patients diagnosed with depression in a hospital regime are registered. Hence, data is unique with no selection bias. The main purpose of the database is not only to improve quality in treatment and care of patients with depressions but also to make epidemiological research possible. In spite of several years of existence, problems exist regarding completeness of some of the data reported by the clinicians, which hinders use of the database's full potential.

\section{Acknowledgment}

This paper was funded by the Program for Clinical Research Infrastructure (PROCRIN) established by the
Lundbeck Foundation and the Novo Nordisk Foundation and administered by the Danish Regions.

\section{Disclosure}

The authors report no conflicts of interest in this work.

\section{References}

1. Ellervik C, Kvetny J, Christensen KS, Vestergaard M, Bech P. Prevalence of depression, quality of life and antidepressant treatment in the Danish General Suburban Population Study. Nord J Psychiatry. 2014;68(7):507-512.

2. Olsen LR, Mortensen EL, Bech P. Prevalence of major depression and stress indicators in the Danish general population. Acta Psychiatr Scand. 2004;108:96-100.

3. World Health Organization. The World Health Report 2008 - Primary Health Care (Now More Than Ever). Geneva, Switzerland: World Health Organization. Switzerland Office of Publications; 2008:1-16.

4. Lassemo E, Sandanger I, Nygård JF, Sørgaard KW. Predicting disability pension - depression as hazard: a 10 year population-based cohort study in Norway. Int J Methods Psychiatr Res. Epub 2015 Jun 22.

5. Nierenberg AA. Long-term management of chronic depression. J Clin Psychiatry. 2001;62 Suppl 6:17-21.

6. Federation of Danish Employers (2010). Arbejdsmarkedsrapport 2010 [Labour market report 2010].

7. Bauer J, Okkels N, Munk-Jørgensen P. State of psychiatry in Denmark. Int Rev Psychiatry. 2012;24(4):295-300.

8. Mainz J, Krog BR, Bjørnshave B, Bartels P. Nationwide continuous quality improvement using clinical indicators: the Danish National Indicator Project. Int J Qual Health Care. 2004;16 Suppl 1:i45-50.

9. Cuijpers P, Smit F. Excess mortality in depression: a meta-analysis of community studies. J Affect Disord. 2002;72(3):227-236.

10. Bridge JA, Barbe RP. Reducing hospital readmission in depression and schizophrenia: current evidence. Curr Opin Psychiatry. 2004; 17:505-511.

11. Nelson EA, Maruish ME, Axler JL. Effects of discharge planning and compliance with outpatient appointments on readmission rates. Psychiatr Serv. 2000;51:885-889.

12. Qin P, Nordentoft M. Suicide risk in relation to psychiatric hospitalization: evidence based on longitudinal registers. Arch Gen Psychiatry. 2005;62(4):427-432.

13. The report from 2014 in Danish can be downloaded from: https:// www.sundhed.dk/content/cms/25/14325_årsrapport_depression_ 2014_300615.pdf. Accessed January 20, 2016.

14. Info on RKKP in English [homepage on the Internet]. Aarhus: Databasernes Fællessekretariat. Available from: http://www.rkkp.dk/inenglish/. Accessed January 20, 2016.

\section{Clinical Epidemiology}

\section{Publish your work in this journal}

Clinical Epidemiology is an international, peer-reviewed, open access, online journal focusing on disease and drug epidemiology, identification of risk factors and screening procedures to develop optimal preventative initiatives and programs. Specific topics include: diagnosis, prognosis, treatment, screening, prevention, risk factor modification, Submit your manuscript here: http://www.dovepress.com/clinical-epidemiology-journal

\section{Dovepress}

systematic reviews, risk \& safety of medical interventions, epidemiology \& biostatistical methods, and evaluation of guidelines, translational medicine, health policies \& economic evaluations. The manuscript management system is completely online and includes a very quick and fair peer-review system, which is all easy to use. 